\title{
Movement patterns drive within-mudflat distribution of an intertidal amphipod
}

\author{
David Drolet $^{1,2, *}$, Myriam A. Barbeau ${ }^{1}$ \\ ${ }^{1}$ Department of Biology, University of New Brunswick, Fredericton, New Brunswick E3B 5A3, Canada \\ ${ }^{2}$ Present address: Biology Department, Mount Allison University, Sackville, New Brunswick E4L 1G7, Canada
}

\begin{abstract}
Spatial structuring in species distribution can be caused by effects of biotic or abiotic factors on the vital rates (survival, growth or reproduction) or movement of individuals. Here, we studied the distribution patterns of a dominant infaunal invertebrate, the amphipod Corophium volutator, on an intertidal mudflat and evaluated the relative contribution of vital rates and movement on the formation of intermediate-scale patterns (10 to $100 \mathrm{~m}$ ). We found a clumped distribution at scales ranging from 0.2 to $100 \mathrm{~m}$ and occasionally the presence of large-scale gradients. At intermediate scales, variation in density in the mud associated better with variation in movement variables (density of swimmers and immigration) than demographic variables. Predictions from local population models not including migration often largely underestimated increases in local density, leaving immigration as the only mechanism explaining variation in density. Amphipod swimming was directed, and the direction of swimming corresponded to overall density gradients observed on the mudflat. We concluded that movement of $C$. volutator is an important process causing and maintaining intermediate-scale distribution patterns. Spatial variability in supply of individuals, likely linked to timing of swimming coupled with hydrodynamic conditions, translates into notable variation in population density distributions.
\end{abstract}

KEY WORDS: Spatial patterns $\cdot$ Soft sediment $\cdot$ Dispersal $\cdot$ Immigration $\cdot$ Corophium volutator

\section{INTRODUCTION}

Populations and communities are generally spatially structured (Legendre \& Fortin 1989) as a result of factors operating over a range of scales (Levin 1992). Spatial structuring of populations can arise from spatial variability in vital rates, movement, or a combination of both. If vital rates (survival, growth, or reproduction) vary in space, density will vary accordingly. For example, reduced survival in zones dominated by a competitor can exclude or reduce density of a lesser competitor (e.g. Connell 1961). For motile species, spatial variation in time spent moving, displacement speed, or turning angles create spatial structure (Turchin 1991). In patches where conditions are beneficial, individuals can turn more frequently, resulting in aggregation in these areas (e.g. Coffin et al. 2008). Arrival of new individuals into a population through dispersal can influ- ence population density as emphasized by the ideas of supply-side ecology (Underwood \& Keough 2001).

In intertidal soft-sediment environments, various spatial patterns in species distribution, such as patches or gradients, have been observed (Thrush et al. 1989, Hewitt et al. 1997). Distribution of individuals can be influenced by species interactions (Woodin 1974, Wilson 1989), animal-sediment interactions (Meadows 1964, Gray 1974, Snelgrove \& Butman 1994), indirect interactions mediated by a bioengineering species (Reise 2002), and disturbance (e.g. Commito et al. 1995). Only recently has attention focused on movement of individuals. Bedload transport of post-settlement juveniles was measured (Roegner et al. 1995, Norkko et al. 2001, Jennings \& Hunt 2009) and shown to play a role in distribution patterns of species (Emerson \& Grant 1991, Commito et al. 1995, Hewitt et al. 1997, Zajac 2004). In addition, some species actively 
emerge from the sediment and drift in the water column as post-settlement juveniles or adults (Hughes 1988, Armonies 1992, Gunther 1992, Cummings et al. 1995, Drolet \& Barbeau 2009a), with consequences on local population dynamics (Junkins et al. 2006). The relatively high motility of soft-sediment species can have opposing effects on spatial structuring: it may mask effects of other factors by homogenizing densities (e.g. rapid recolonization of disturbed areas; Thrush et al. 1991) or create spatial patterns (e.g. migration of some post-settlement juvenile mollusks; Armonies \& Hartke 1995, Armonies 1996).

The upper Bay of Fundy on the western North Atlantic coast has the highest tidal amplitude in the world (Desplanque \& Mossman 2004) and extensive intertidal mudflats (some are $>10 \mathrm{~km}$ wide along-shore with a $2 \mathrm{~km}$ long intertidal area). On these mudflats, the burrow-dwelling amphipod Corophium volutator is often the dominant macro-invertebrate, with densities reaching $>50000$ ind. $\mathrm{m}^{-2}$ (Peer et al. 1986). Populations of this amphipod have a sex ratio biased towards females (Barbeau et al. 2009), and low abundance of males can limit the reproductive output of a population (Forbes et al. 2006). The spatial distribution of $C$. volutator throughout its geographic range (eastern and western North Atlantic coast) is clumped at many spatial scales (Flach 1996). At the scale of several kilometers, variations in density can be related to temperature and salinity (Mills \& Fish 1980), sediment type (Flach 1996) and configuration of the shore (Hughes \& Gerdol 1997). At much smaller scales (centimeters to meters), density is influenced by various biotic and abiotic factors (e.g. Meadows 1964, Wilson 1989, Drolet \& Barbeau 2009b). C. volutator is a relatively motile species; it moves over short distances by crawling at the surface of the mud during emersion (Boates \& Smith 1989), and over larger distances by swimming during immersion periods, especially those occurring at night around new and full moons (Drolet \& Barbeau 2009a). Consequences of large-scale dispersal of $C$. volutator on its within-mudflat distribution have not yet been assessed.

The main goal of our present study was to evaluate the contribution of variation in vital rates versus movement patterns on the formation of within-mudflat spatial patterns in Corophium volutator. We first quantified patterns in distribution of $C$. volutator at multiple spatial scales ( 0.2 to $2000 \mathrm{~m})$ at our focal mudflat. We then studied intermediate-scale (10 to $100 \mathrm{~m}$ ) variability in demographic and movement variables. We correlated the different variables with $C$. volutator density in an attempt to identify probable causes of formation of patterns at this scale. Finally, we compared the observed local (10 to $100 \mathrm{~m}$ ) population trajectories of C. volutator with the predictions of a non-spatial population model fitted for the entire mudflat, to further investigate the relative contribution of vital rates and movement on density at this scale.

\section{MATERIALS AND METHODS}

Sampling program. We worked on the mudflat of Pecks Cove, Cumberland Basin, upper Bay of Fundy, eastern Canada (Fig. 1A). We sampled the mudflat from May 2006 to July 2007 (mid-May, early June, midJune, early July, mid-July, early August, mid-August, late September and mid-November in 2006, and midApril, mid-May, mid-June and mid-July in 2007) along 7 transects (each $550 \mathrm{~m}$ long) running perpendicular to
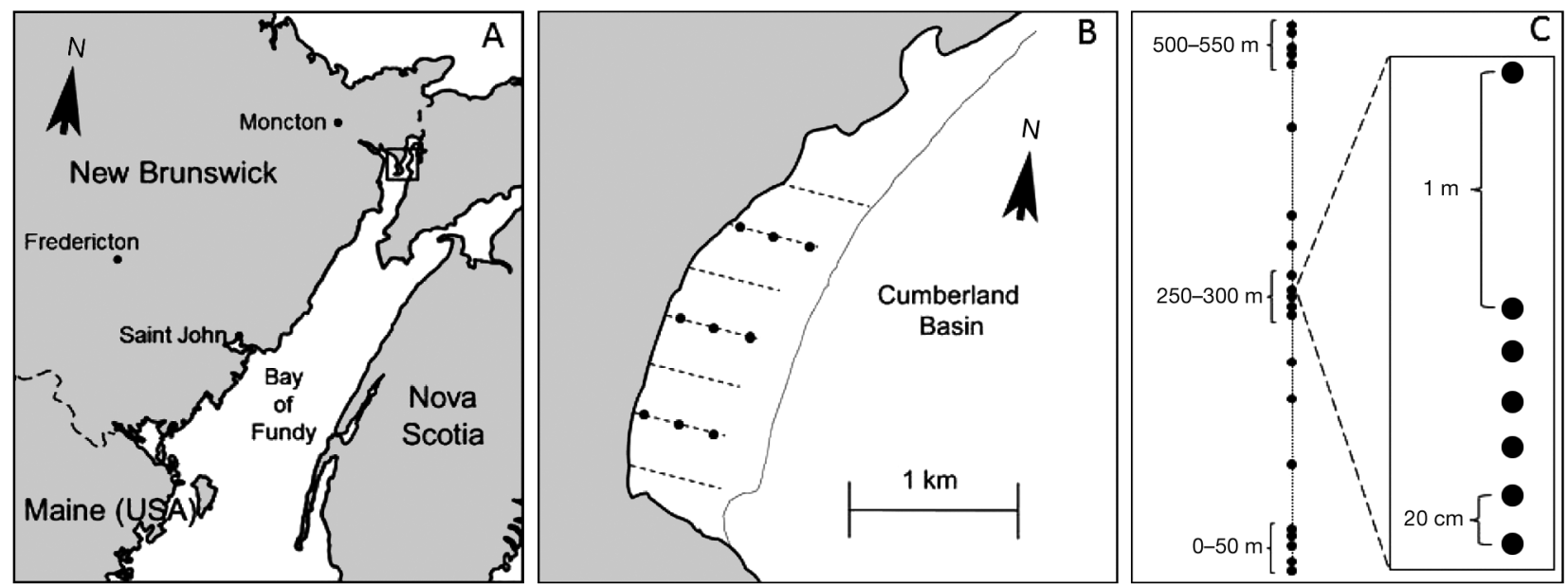

Fig. 1. (A) The location of the study site in the Bay of Fundy, Canada. (B) The mudflat of Pecks Cove. Dashed lines: 7 sampling transects with 9 stations $(\bullet, 3$ on each of the north, middle and south transects) where movement variables were measured. (C) Details of the location of the samples collected on each transect 
the line of low water and separated by $300 \mathrm{~m}$ (Fig. 1B). On each sampling occasion and on each transect, we collected 27 core samples $(6.5 \mathrm{~cm}$ diameter, to the depth of the hypoxic layer) as follows: (1) 5 random samples at each of 3 distance zones (near, intermediate and far: 0 to $50 \mathrm{~m}, 250$ to $300 \mathrm{~m}$ and 500 to $550 \mathrm{~m}$ from shore, respectively), (2) 3 random samples between 50 and $250 \mathrm{~m}$ and between 300 and $500 \mathrm{~m}$ from shore (i.e. between the near- and mid-distance zones, and the midand far-distance zones), and (3) samples at 20,40,60, 80,100 and $200 \mathrm{~cm}$ from 1 of the random samples taken in Case 1 or 2 (Fig. 1C). Our sampling protocol ensured that we had good replication near-shore, mid-shore, and far from shore (1), good representation over the whole mudflat (1 \& 2), and samples at small spatial scales (3). Once collected, core samples were sieved through a $250 \mu \mathrm{m}$ mesh (Crewe et al. 2001) and preserved in $95 \%$ ethanol. The number of Corophium volutator individuals in each sample was later quantified under a dissecting microscope.

Demographic variables. The samples collected in the 3 distance zones were further processed for demographic variables likely to influence overall density. Specifically, we calculated proportion of individuals that were small juveniles (1 to $2 \mathrm{~mm}$ body length, from tip of rostrum to end of telson), big juveniles (2 to $4.5 \mathrm{~mm}$ ) and adults $(>4.5 \mathrm{~mm})$, the proportion of adults that were females and the proportion of females that were ovigerous for each sample. We used a Folsom plankton splitter to obtain sub-samples for very large samples (>200 individuals).

Movement patterns. We examined movement of Corophium volutator at 9 stations on the mudflat; 1 station in each of the 3 distance zones of 3 transects (Fig. 1B). We measured movement variables at $2 \mathrm{wk}$ intervals during summer 2006, twice in fall 2006 and twice in summer 2007, at approximately the same dates as in the sampling program above.

We performed a mark-recapture experiment at the 9 stations during the summer months to quantify spatial and temporal variation in emigration and immigration rates of Corophium volutator. We released a known number of marked individuals, and, after $1 \mathrm{~d}$, quantified the number of marked individuals still present in the release areas (to estimate the number that departed from the areas), and the number of unmarked individuals that moved in the release areas (to estimate immigration).

The experimental units consisted of PVC pipes ( $7.5 \mathrm{~cm}$ diameter, $7 \mathrm{~cm}$ long) sunk in the mud until the top was levelled with the substratum. The mud contained in the pipes was scooped out to the depth of the hypoxic layer and replaced by mud collected near each station and sieved through $250 \mu \mathrm{m}$ mesh to remove all Corophium volutator individuals (Crewe et al. 2001) and other macro-organisms. At each station, 6 experimental units were deployed about $50 \mathrm{~cm}$ off the sides of a fixed wooden plank, used for walking to minimize disturbance by workers. C. volutator individuals were marked by immersion in $50 \mathrm{mg} \mathrm{l}^{-1}$ solution of neutral red (Drolet \& Barbeau 2006). Mark-recapture trials were not conducted in the fall or spring, as the weather was too cold to stain amphipods properly (Drolet \& Barbeau 2006). We released 20 marked C. volutator (taken from the dominant size class present on the mudflat at the time of a trial) into each experimental unit and placed a mesh cover on top of the unit (Drolet \& Barbeau 2009b) for $\sim 12 \mathrm{~h}$, to prevent amphipods from moving as a result of recent disturbance. A trial started upon removal of covers and ended after $24 \mathrm{~h}$. The mud contained in the pipes was then collected and sieved (250 $\mu \mathrm{m}$ mesh). The numbers of marked amphipods recovered alive were counted immediately. The rest of the samples was preserved in $95 \%$ ethanol, and the number of unmarked C. volutator (that immigrated into the release area) was later quantified under a dissecting microscope.

We measured the abundance of Corophium volutator swimmers at each of the 9 stations by deploying 3 replicate plankton nets $(60 \mathrm{~cm}$ long, $20 \mathrm{~cm}$ diameter circular opening and mesh size of $180 \mu \mathrm{m}$ ) that were free to rotate ( $1 \mathrm{~m}$ above the substratum) at the top of a rebar placed in the mud. The nets were deployed for 1 high tide occurring at night, since this is when most of the swimming occurs (Drolet \& Barbeau 2009a). The matter collected by the nets was preserved in $95 \%$ ethanol, and the number of $C$. volutator individuals in the samples was later quantified under a dissecting microscope. A large amount of drifting matter was collected on many occasions, and we used a Folsom plankton splitter to subsample (sample splitting ranged from $1: 1$ to $1: 64$ ).

We calculated the density of swimming amphipods (individuals per cubic meter of water) by dividing counts of amphipods captured in each net by the volume of water filtered by the nets. This volume of water was estimated using the dissolution rate of a plaster hemisphere attached near the mouth of each net (Komatsu \& Kawai 1992). The method was calibrated in a saltwater flume.

We also evaluated the spatial and temporal variation in the mean direction of swimming of Corophium volutator using stationary plankton nets facing different directions. Specifically, a set of 4 nets (as described above) was deployed at each station, with 1 net facing south, east, north, or west. The samples were processed as described above.

Data analysis. We used Moran's I index of autocorrelation to quantify spatial patterns in distribution of Corophium volutator in the mud (Legendre \& Fortin 
1989). For each sampling occasion, we calculated the index for samples spaced by different intervals ranging from 0.2 to $2000 \mathrm{~m}$ (see 'Results' for exact distance intervals). Moran's I index for a given distance interval was declared significant if the value was outside the $95 \%$ confidence intervals predicted by the null hypothesis of no spatial association (or random distribution). The confidence intervals were calculated by a randomization procedure, in which we randomly distributed the measured densities to the different sampling locations, and calculated Moran's I for each distance interval for the randomly generated dataset. This was repeated 1000 times, and the 25th and 975th largest values were retained as the limits of the confidence intervals. We also used general linear models and variance components analysis to examine the spatial structure of density, demographic variables and movement variables (in the supplement at www.int-res.com/ articles/suppl/m431p255_supp.pdf).

To analyze the direction of swimming, we calculated the mean direction of swimming for each sampling occasion and station. We used the proportion of individuals swimming in different directions (individuals caught in a net divided by the total number of individuals caught in the 4 nets at a particular station) to calculate mean vector length and orientation (Batschelet 1981). We used the mean vector for each sampling date as a replicate value, and performed a parametric, 1-sample, second-order analysis of angles (Zar 1999) to determine if amphipods swim in a particular direction at each station.

To gain insight on mechanisms responsible for the variation in Corophium volutator density within the mudflat, we evaluated how the different demographic and movement variables co-varied with density using Pearson's correlation analyses. (1) We calculated the average value for each location (Distance zone $\times$ Transect) for density and demographic variables and for each station for movement variables; thus, location or station was the unit of replication. (2) We removed temporal variation by transforming the variables to an adjusted residual: (observed value at the location average for the mudflat at a time period) / average for the mudflat at a time period. Thus, a value of 0.5 for a variable at a location indicates that, at this location, the variable is $50 \%$ higher than the average for the mudflat at that time. These residuals adjusted for seasonal variation were now comparable between dates, and this enabled us to focus on spatial variation within the mudflat independent of the effect of season. (3) Since the spatial relationship between $C$. volutator density and the different variables may change over the time, we tested for an interaction between time (date of sampling; a categorical variable) and the adjusted residuals of the different variables (continuous) on the adjusted residuals of density (the response variable) using an ANCOVA model. The interaction was significant for 2 variables, proportion of small juveniles $\left(F_{9,189}=2.42, \mathrm{p}=0.01\right)$ and proportion recaptured $\left(F_{7,56}=2.83, \mathrm{p}=0.01\right)$, and so we conducted a Pearson's correlation analysis between adjusted residuals of density and of each of these 2 variables for each sampling time. For the other variables (transformed to adjusted residuals), there was no interaction with time, and so we pooled over sampling times and then conducted the Pearson's correlation analyses.

To further investigate the relative contribution of vital rates and movement on the formation of spatial patterns within a mudflat, we compared the changes in Corophium volutator density predicted by a population model to the observed changes in density for each location (the 21 transect and distance zone combinations). (1) We developed a stage-based matrix model (Caswell 2001) with 3 stages: small juveniles (1 to $2 \mathrm{~mm}$ body length), big juveniles ( 2 to $4.5 \mathrm{~mm}$ ) and adults (>4.5 mm) (Fig. 2). The model is of the form:

$$
\mathbf{n}_{t+1}=\mathbf{A} \mathbf{n}_{t}
$$

where $\mathbf{n}$ is a vector of the density (ind. $\mathrm{m}^{-2}$ ) in the different stages at time $t$ and $\mathbf{A}$ is the transition matrix:

$$
\left[\begin{array}{lll}
a_{11} & 0 & a_{13} \\
a_{21} & a_{22} & 0 \\
0 & a_{32} & a_{33}
\end{array}\right]
$$

containing the different transition probabilities $\left(a_{i j}\right)$. We used a time step (from $t$ to $t+1$ ) of $2 \mathrm{wk}$. (2) We parameterized the transition matrix empirically by minimization of the squared differences between observed size distributions (collected every $2 \mathrm{wk}$ ) and model predictions for the period from May to August 2006. We chose this period because we had regular sampling intervals and $C$. volutator population dynamics were the most rapid. Since very few ovigerous

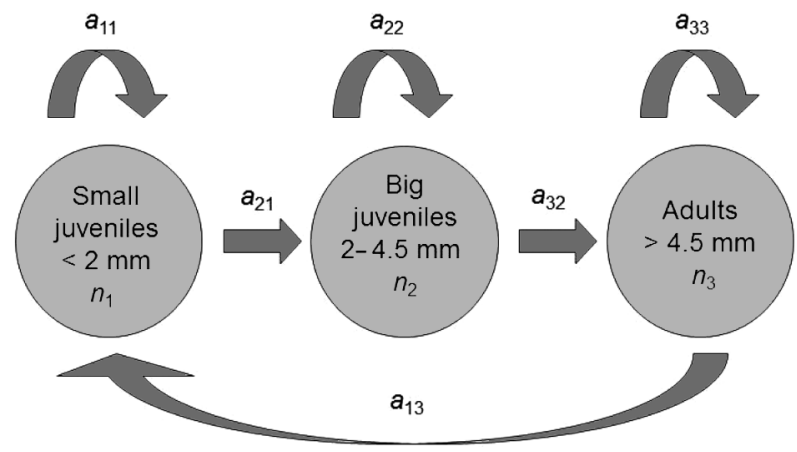

Fig. 2. Corophium volutator. Life cycle diagram for the matrix model used to estimate population structure. $n_{1}, n_{2}$ and $n_{3}$ represent the density of amphipods in each of the 3 stages (Stage 1: small juvenile; Stage 2: big juvenile; Stage 3: adult) at a given time $t$, and $a_{i j}$ represents the transition coefficient from Stage $j$ to Stage $i$ over a time step of $2 \mathrm{wk}$ 
females were found after the mid-July sampling, reproduction was set to 0 afterwards. The observed size distribution for a given sampling time was obtained from pooling all samples from the mudflat; thus, the model describes population dynamics assuming a closed population without dispersal or variation in vital rates. (3) We evaluated local trends in dynamics by comparing the observed change in density of the different stages at each location with the prediction of the model. This was done for each time step separately (for the summer months of both years), i.e. population projection at time $t+1$ was calculated from the observed size distribution at time $t$ using Eq. (1). To assess the correspondence between the observed local distribution and the model's prediction, we calculated the ratio of observed and predicted densities for the different stages (small juveniles, big juveniles and adults) at each time step, and plotted the frequency distribution of the $\log _{10}$-transformed ratios. If the model perfectly predicts densities, then the value of the log-ratio should be 0 . A value of 1 represents an observed density 1 order of magnitude over the prediction, and a value of -1 is an observed density 1 order of magnitude under the prediction. By analyzing the direction and magnitude of the departures, we evaluated the most likely causes of local variation in population dynamics (i.e. vital rates or movement).

\section{RESULTS}

\section{Distribution patterns}

Analysis of spatial autocorrelation revealed a clumped distribution of Corophium volutator for all sampling dates (Fig. 3). In general, Moran's $I$ indices
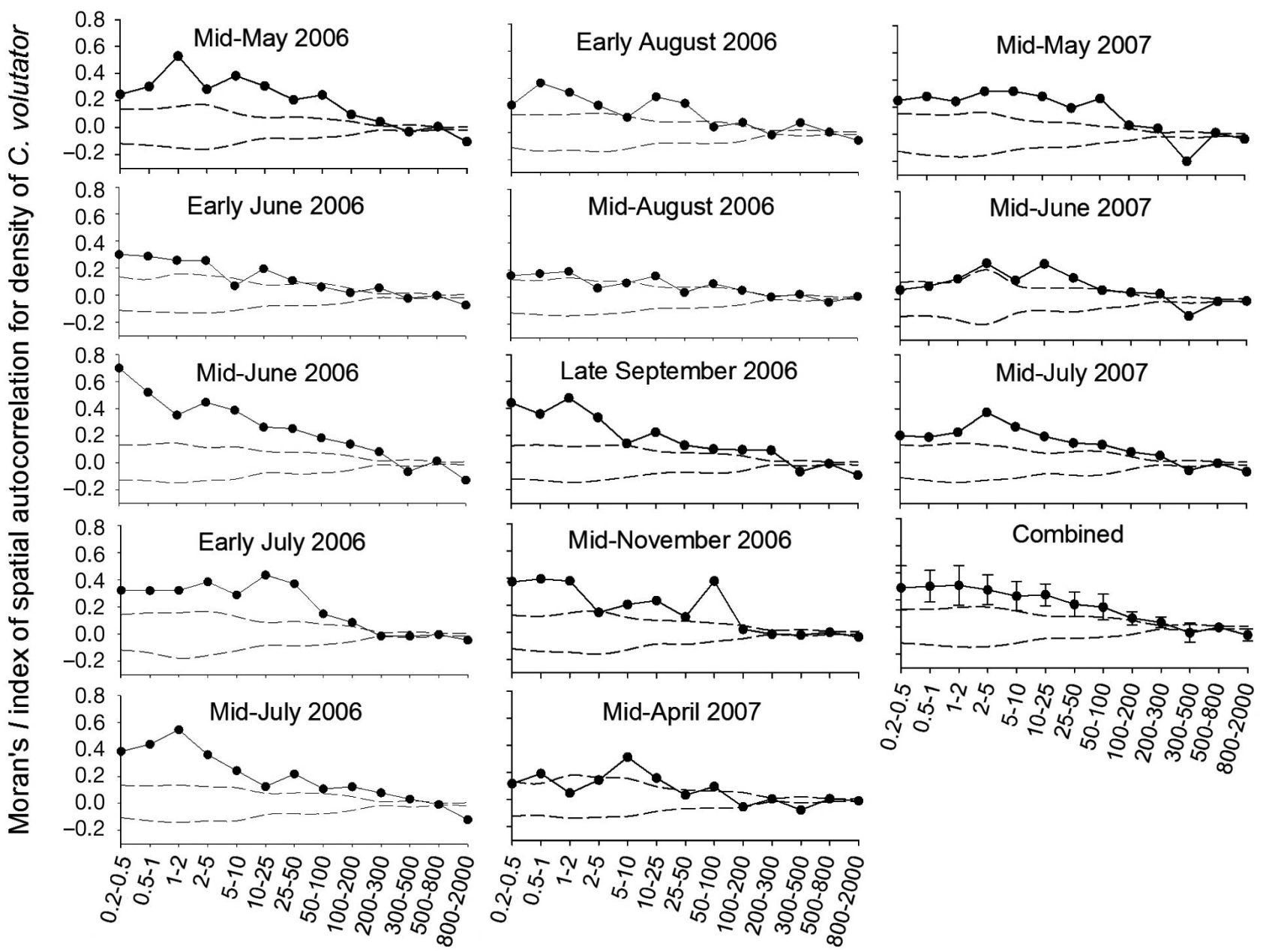

\section{Distance interval $(\mathrm{m})$}

Fig. 3. Corophium volutator. Spatial correlograms of density in the mud at the different sampling times at Pecks Cove. --: observed Moran's I index for the distance intervals; ---: 95\% confidence intervals of the null hypothesis of random distribution calculated by randomization procedures 
were high for the smaller distance intervals and decreased with increasing distance between samples. Indices for distance intervals > $200 \mathrm{~m}$ were generally non-significant. However, on some occasions, the largest distance intervals (500 to 800 and 800 to $2000 \mathrm{~m}$ ) had significant negative values, suggesting the presence of gradients in density for these dates. When all sampling dates were pooled, all distance intervals $<200 \mathrm{~m}$ were significantly $>95 \%$ confidence intervals.

Visual examination of the spatial distribution of Corophium volutator density (represented as adjusted residuals to remove seasonal effects) over the whole mudflat (Fig. 4) indicated that density was generally lower to the north of the mudflat and further from shore.

\section{Direction of swimming}

At all stations and on most occasions, Corophium volutator individuals tended to swim along shore, towards the south (Fig. 5). The analysis revealed significant orientation everywhere, except for the stations at from 500 to $550 \mathrm{~m}$ offshore on the north and south transects.

\section{Density versus demographic and movement variables}

Of the demographic variables investigated (Fig. 6A to C), only proportion of small juveniles associated with the density of Corophium volutator in the mud (Fig. 6A, Table 1). Early in the summer and in the fall, there was no link between the 2 variables. On most occasions during the summer, there was a significant positive correlation between adjusted residuals of proportion of small juveniles and adjusted residuals of density. In August, the trend was reversed, and zones with high densities had a smaller proportion of small juveniles. There was no association between density and proportion of females, or between density and proportion of ovigerous females (Fig. 6B,C).

Movement variables showed a stronger association with density of amphipods in the mud (Fig. 6D to F).
Although, adjusted residuals of proportion of marked individuals that were recaptured showed a timevariable association with adjusted residuals of density, none of the correlations for the different sampling times were significant (Fig. 6D, Table 1). Density of immigrants and density of swimmers both had a significant positive correlation with amphipod density in the mud (Fig. 6E,F).

The population matrix model that was fitted to the time series of Corophium volutator size distribution for the summer of 2006 for the whole mudflat represented spatially averaged population dynamics very well (Fig. 7). The predicted timing of appearance of small juveniles and their later decline in density were well matched to observed data. The increase in density of big juveniles in July and the dynamics of adult density were also well described by the model. However, the model did not capture the decrease in density of the 2 largest size classes in August. This is probably because this simple model does not include predation by migratory sandpipers, which arrive yearly in the area in midJuly (Hicklin 1987). Overall, the model is a good descriptor of spatially averaged population dynamics

Table 1. Corophium volutator. Pearson's correlation coefficients (r) between the adjusted residuals of density in the mud and those of a proportion of small juveniles and a proportion of marked individuals recaptured for the different sampling dates at Pecks Cove. Significant r-values $(\alpha=0.05)$ are presented in bold. The degrees of freedom (df) for the analyses for each variable are also given. NA: not available

\begin{tabular}{|lcc|}
\hline Period & $\begin{array}{c}\text { Proportion of small } \\
\text { juveniles }(\mathrm{df}=20)\end{array}$ & $\begin{array}{c}\text { Proportion } \\
\text { recaptured }(\mathrm{df}=8)\end{array}$ \\
\hline $\mathbf{2 0 0 6}$ & & $\mathrm{NA}$ \\
Early Jun & 0.12 & 0.03 \\
Mid-Jun & $\mathbf{0 . 4 9}$ & 0.01 \\
Early Jul & $\mathbf{0 . 5 5}$ & 0.63 \\
Mid-Jul & $\mathbf{0 . 7 5}$ & 0.04 \\
Early Aug & -0.30 & 0.36 \\
Mid-Aug & $\mathbf{- 0 . 5 3}$ & 0.04 \\
Late Sep & 0.11 & -0.54 \\
2007 & & -0.57 \\
Mid-Jun & 0.17 & \\
Mid-Jul & $\mathbf{0 . 6 5}$ & \\
\hline
\end{tabular}

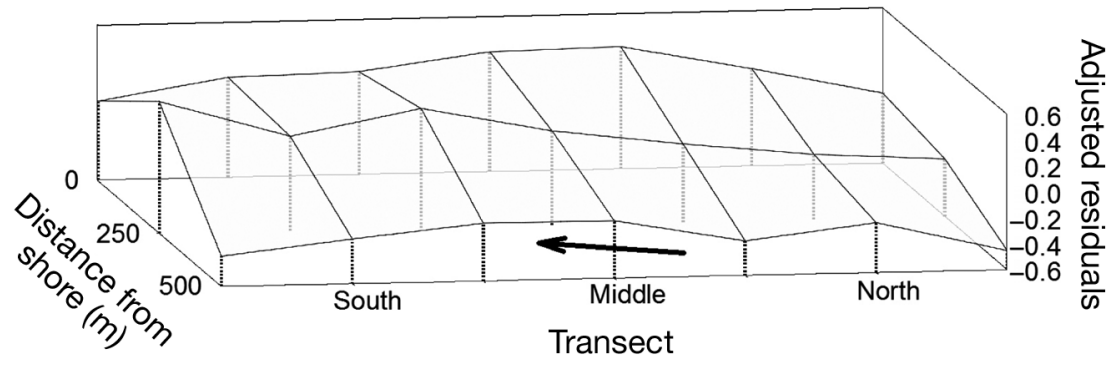

Fig. 4. Corophium volutator. Distribution on the mudflat of Pecks Cove represented as adjusted residuals in density (averaged over all sampling periods) at the different locations $(21$ Distance zone $\times$ Transect combinations). The arrow indicates mean direction of swimming (averaged over all sampling times and stations), obtained from the data presented in Fig. 4. To simplify the presentation, standard errors are not provided 

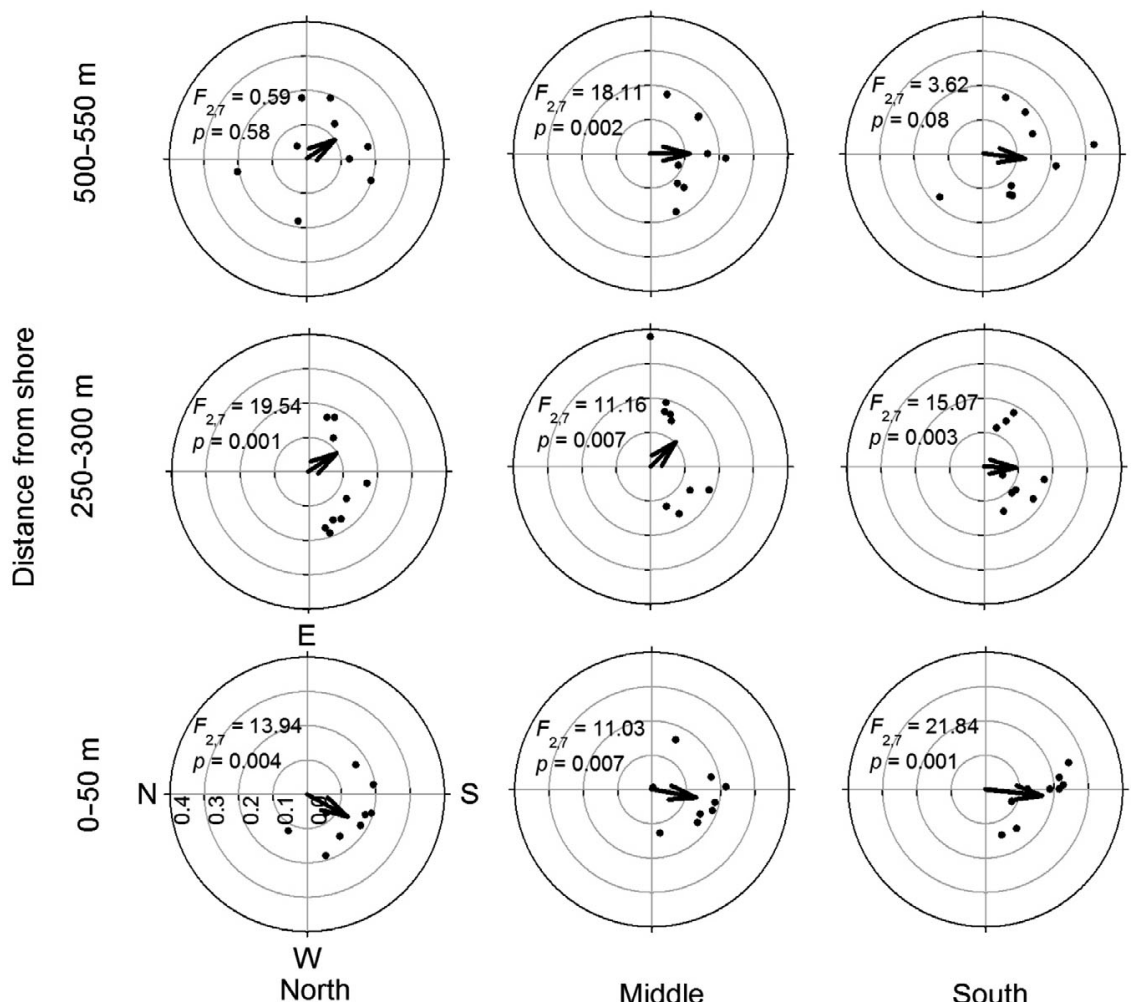

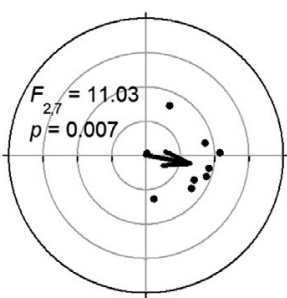

Middle

Transect

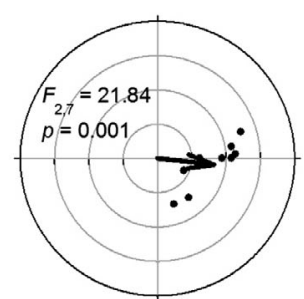

South
Fig. 5. Corophium volutator. Direction of swimming at the 9 stations on the mudflat of Pecks Cove from 2006 to 2007. •: mean vector length and direction (average of the 4 directional nets) for a given sampling time; $\longrightarrow$ : the length and direction of the mean of mean vectors at that station, averaged over sampling times. $F$ and p-values relate to the 1-sample, second-order analysis of angles test for significance in orientation
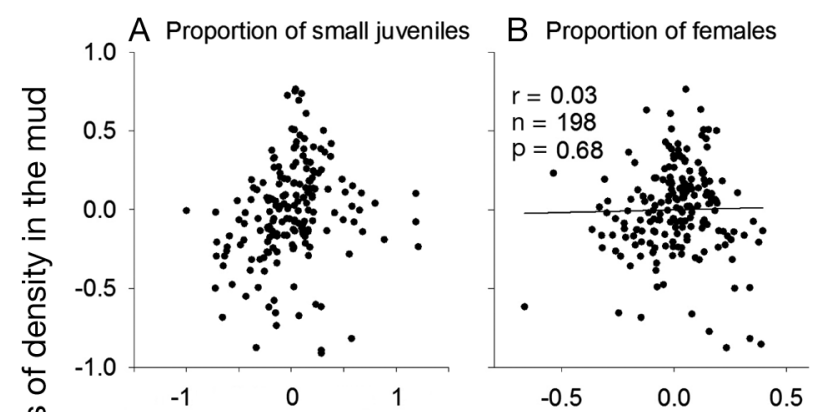

C Proportion of ovigerous females

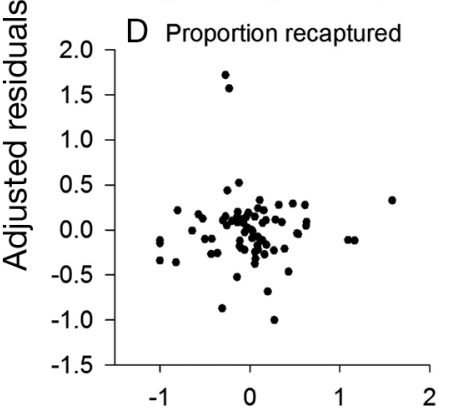

$\mathrm{E}$ Density of immigrants
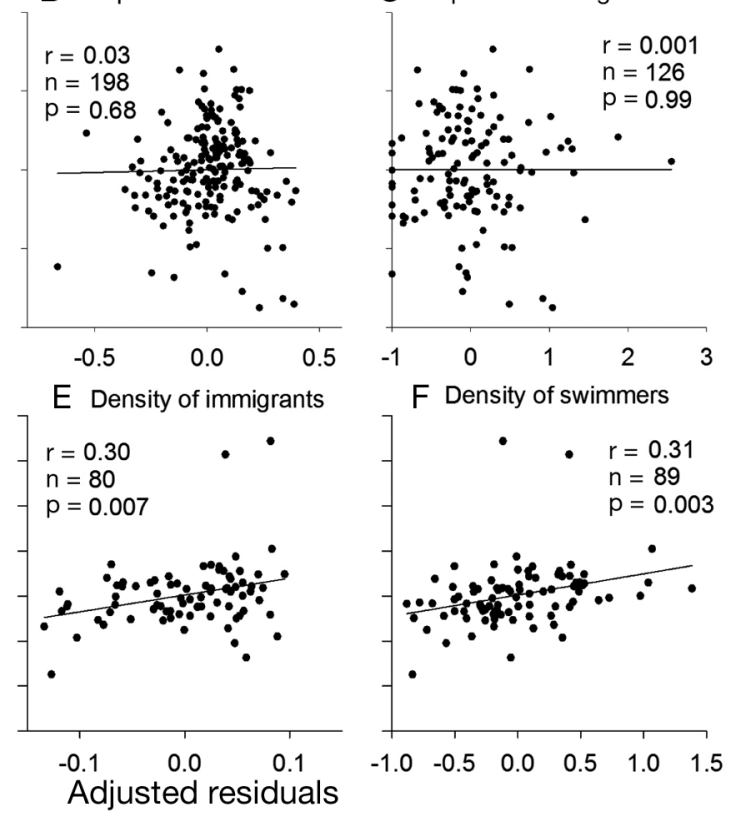

Fig. 6. Corophium volutator. Correlations between adjusted residuals of density in the mud and of demographic (A to C: proportions of small juveniles, females and ovigerous females, respectively) and movement (D to F: proportion recaptured, density of immigrants and density of swimmers) variables from 2006 to 2007 at Pecks Cove. Dot: value (averaged over 3 to 6 sampling units) at a location at each sampling time. There were 21 locations (Distance zone $\times$ Transect combinations) for demographic variables and 9 stations for movement variables, and from 6 to 8 sampling times. The line of best fit is not presented for a proportion of small juveniles and a proportion of marked individuals recaptured because there was an interaction between these variables and time on density (see Table 1); r-, n- and p-values are the results of Pearson's correlation analyses 

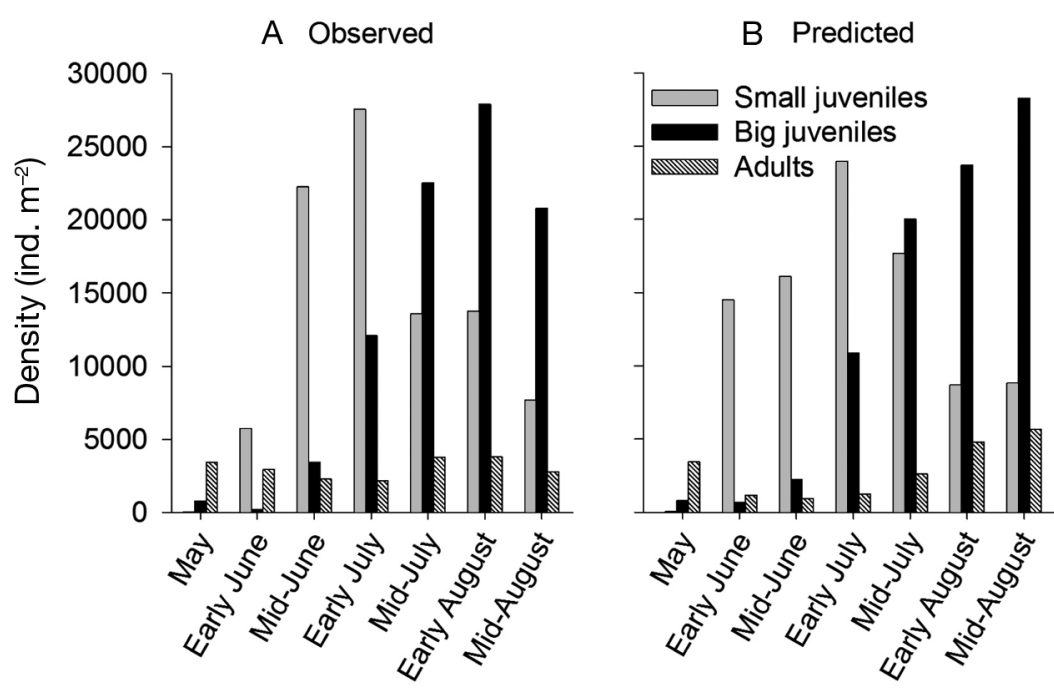

Fig. 7. Corophium volutator. Density in the mud of the 3 stages (size classes) in late spring and summer 2006. The observed time series (A) is for all samples over the mudflat pooled together. Predicted values (B) are from the population matrix model

and can be used as a framework to test variation in local dynamics and demographic output.

When the parameterized transition matrix was used to predict changes in Corophium volutator density on a smaller scale within the mudflat (for each location separately) between 2 sampling times, the match between prediction and observation was not as good (Fig. 8). Although the average log-ratio of observed densities and predicted densities was centered on 0 (Fig. 8A), there were locations where the model did not fit the observed data. On many such occasions, the model under-predicted the density of certain stages by 1 order of magnitude, and, in the worst cases, densities were underpredicted by almost 3 orders of magnitude. In general, when the model did not fit observed data accurately (which we defined as an error by 1 order of magnitude or more), it was because the observed increase in density could not be explained by the model (i.e. the long tail on the right side of the frequency distribution; Fig. 8A). As an example, Fig. 8B shows the observed variations in density of the different stages at 1 location. In July of both years, there was a sudden increase in density that could not be explained by vital rates. The June sampling detected very low densities of adults, and the increase in big juveniles and adults in July could not be explained by reproduction. Also, the density of big juveniles was always higher than that of small juveniles, which is impossible if vital rates drive densities at that location.

\section{DISCUSSION}

We conducted an in-depth study of the distribution pattern of a dominant marine, benthic invertebrate in a large and well-defined habitat (a $\sim 175$ ha mudflat) and assessed the relative importance of vital rates and movement in determining its distribution. We found
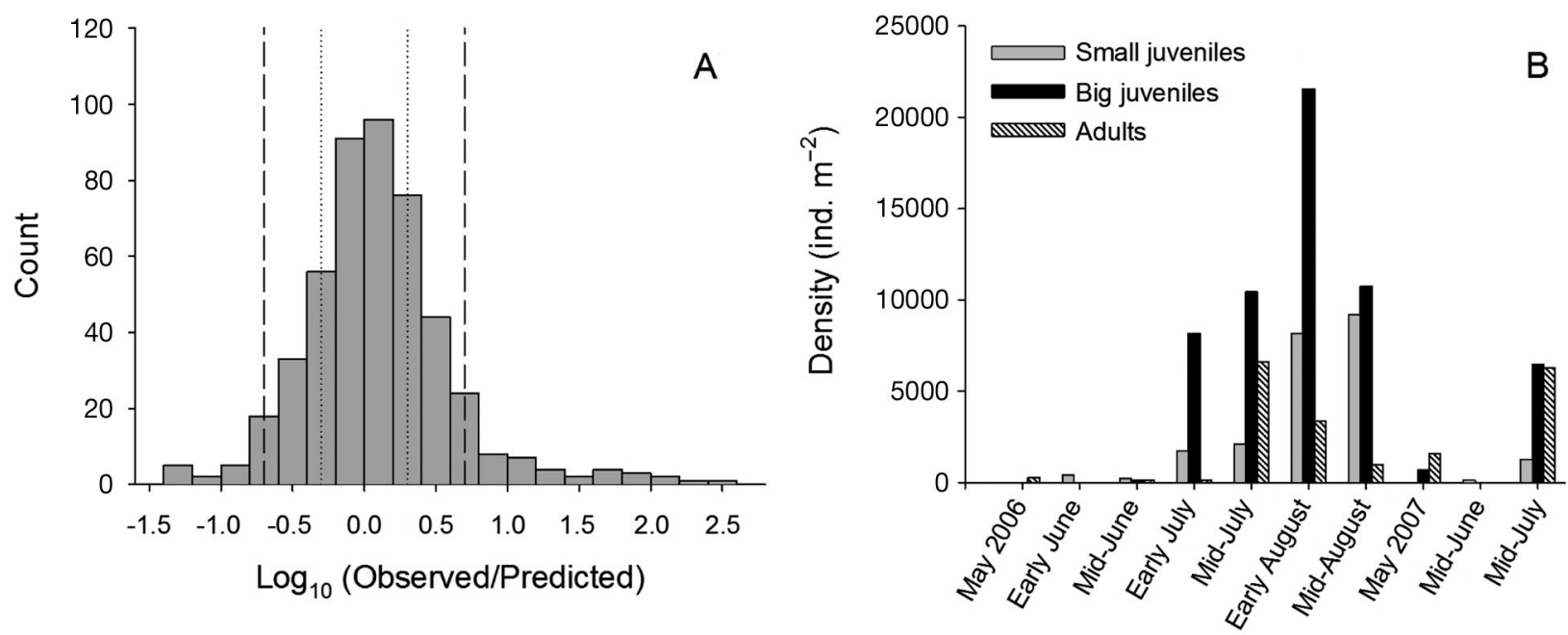

Fig. 8. Corophium volutator. (A) Frequency distribution of the $\log _{10}$-transformed ratio of locally observed density to density predicted by the stage-based matrix model. $X$-axis: orders of magnitude in difference; dotted and dashed lines: a 2- and 5-fold difference, respectively. (B) Example of a time series of density in the mud for the 3 size classes at Pecks Cove: the northernmost transect at a distance of 500 to $550 \mathrm{~m}$ offshore shows irregularities due to immigration 
that the distribution of Corophium volutator was nonrandom at several spatial scales. Similar to Lawrie et al. (2000) and Bergstrom et al. (2002), we detected a clumped distribution at very small scales. However, we found that positive spatial autocorrelations extended much further than previously described ( 0 to 6 and 0 to $30 \mathrm{~cm}$, respectively). At small scales $(20 \mathrm{~cm}$ to $5 \mathrm{~m})$, the spatial patterns on the mudflat of Pecks Cove are likely the result of environmental heterogeneity as, for example, C. volutator is positively influenced by tide pools (Drolet \& Barbeau 2009b) and negatively influenced by aggregations of snails (Drolet et al. 2009), and both factors show patchy distribution at a small scale (Coffin et al. 2008). Patterns varied over time as seen for some species in Hewitt et al. (1997); specifically, the strength of positive autocorrelations at smaller scales ( 0.2 to 0.5 and 1 to $2 \mathrm{~m}$ ) varied between successive sampling rounds (Fig. 3). This is likely linked to the intense swimming events observed around the times of new and full moon (Drolet \& Barbeau 2009a). Intense dispersal will tend to smooth out densities and mask effects of small-scale environmental heterogeneity. Our study detected much larger scale patterns that were not described in previous studies, probably because of the smaller extent compared to ours. We found positive spatial autocorrelations at intermediate scales (10 to $100 \mathrm{~m})$, which we discuss below. Finally, on some occasions, we found significant negative indices of autocorrelations for the largest distance intervals (500 to 800 and 800 to $2000 \mathrm{~m}$ ), which suggest the presence of gradients, both along shore and perpendicular from shore (Fig. 4).

A main goal of our study was to understand possible mechanisms responsible for formation of the intermediate scale $(10$ to $100 \mathrm{~m})$ spatial patterns of Corophium volutator within a mudflat. We did not attempt to identify the factors responsible for the patterns (e.g. sediment type, abundance of food, or bird predation); instead, we were interested in understanding whether the patterns were the result of variation in vital rates or movement patterns. Note that the effect of biotic or abiotic variables on density of $C$. volutator would have to be explained by either a change in vital rate or movement patterns. Our general approach was to quantify the intermediate-scale variation in demographic and movement variables and to determine which ones are correlated with density in the mud. Of the demographic variables investigated, only proportion of small juveniles was correlated with amphipod density on some occasions. Generally, the positive association indicated that areas of high amphipod density had a larger proportion of small juveniles. This could be explained by variation in vital rates over the mudflat if, in some areas, reproductive output is higher and more juveniles are produced locally, thus creating patches of higher density. The question here is then: Are the small juveniles produced locally or do they concentrate in some areas through migration? In other analyses of the same dataset using variance components analysis (Tables S1 \& S2 in the supplement at www.int-res.com/articles/ suppl/m431p255_supp.pdf), we found that density of amphipods in the mud was well structured in space ( $60 \%$ of the variation could be explained by the spatial variables: Transect, Distance from shore and their interactions). Conversely, demographic variables influencing production of juveniles (proportion of adults, proportion of adults that were females and proportion of females that were ovigerous) were much less spatially structured, with 10 to $30 \%$ of the variation explained. The difference in degree of spatial structuring of density compared to that of demographic variables supports the idea that individuals gather in some areas through migration rather than being produced locally. Upon examining the fit between the predictions of the non-spatial population matrix model and the observed local population trends, we noted several anomalies. In the cases when observed densities were lower than model predictions, we cannot assess whether this is the result of mortality, reproductive failure, or emigration. However, the most important disparities (often $>1$ order of magnitude) occurred when observed densities were higher than model predictions. The increases in density over adjacent sampling times were often too important to be explained by reproduction. We also observed jumps in density of big juveniles and adults that could not be explained by growth of small juveniles.

Our variance components analysis (Tables $\mathrm{S} 1 \& \mathrm{~S} 2$ in the supplement) showed that movement variables were spatially well structured, with the amount of variation explained by space similar to that of density in the mud ( $\sim 50$ to $60 \%)$. Also, in the present study, we found that immigration and density of individuals swimming in the water column correlated well with variation in density in the mud. Finally, amphipods, on average, swam towards the south of the mudflat with a slight bias towards the shore, which is consistent with the distribution pattern on the mudflat, summarized in Fig. 4. The directed swimming might explain the presence of the gradients that were occasionally detected by the autocorrelation analysis. Overall, withinmudflat distribution patterns of Corophium volutator are more likely produced by dispersal rather than by local variation in vital rates. Furthermore, movement of individuals is the only possible explanation for the jumps in density observed at many locations and on many occasions. Given the abundance of individuals swimming in the water column on a daily basis (Drolet \& Barbeau 2009a) and the potentially long dispersal distances (amphipods are frequently caught swimming 3 to $4 \mathrm{~m}$ over the substrate; Bringloe 2011), we con- 
cluded that movement is an important mechanism underlying the distribution patterns of C. volutator on the mudflat of Pecks Cove. Our study was conducted over 14 mo at 1 site, but ongoing work throughout the upper Bay of Fundy shows important swimming at all mudflats investigated, suggesting the same mechanisms may apply elsewhere (Bringloe 2011).

In intertidal soft-sediment systems throughout the world, the importance of post-settlement movement is becoming widely accepted. Passive and active re-suspension of individuals periodically redistributes individuals and influences distribution patterns (e.g. Commito et al. 1995, Norkko et al. 2001). In most previous studies, the effects of movement were detected at small scales, with movement homogenizing densities and masking the effects of disturbance through recolonization (e.g. Thrush et al. 1991). Other studies detected small-scale variation in movement patterns in relation to variation in environmental conditions leading to formation of spatial structure (e.g. Drolet \& Barbeau 2009b, Drolet et al. 2009). This general concept that variations in movement patterns create spatial structuring applies at larger scales. For example, Hughes \& Gerdol (1997) suggested that swimming at flood tide would result in retention of individuals in tidal creeks and enclosed bays, resulting in higher densities of Corophium volutator in sheltered locations compared to open mudflats. Finally, long-range dispersal has been reported to cause important episodic migrations of specific-size classes of intertidal softsediment species (e.g. Armonies \& Hartke 1995, Armonies 1996, Bouma et al. 2001). Here, we report a direct link between intensity of immigration and intermediate-scale $(10$ to $100 \mathrm{~m})$ spatial patterns, showing that variation in movement patterns at this scale influences distribution of individuals. Our study species moves throughout the summer months, and all size classes drift in the water column (Drolet \& Barbeau 2009a), resulting in long-lasting effects on the 10 to $100 \mathrm{~m}$ spatial patterns. Spatial variability in the supply of individuals, likely linked to the timing of swimming coupled with hydrodynamic conditions, translates into notable variation in population density. As emphasized by the ideas of supply-side ecology (Underwood \& Keough 2001), factors affecting transport, retention and settlement of individuals at relevant spatial scales should be investigated, as they have the potential to strongly influence distribution of infauna.

Acknowledgements. We are grateful to A. Botta, M. Coffin, S. Danielescu, J. Horsefall, A. Jimmo, J. Ritchie and A. Savoie for their help in the field and laboratory. D. J. Hamilton helped with the logistics of field work and provided laboratory space. D. J. Hamilton, J. van de Koppel, J. Watmough and 3 anonymous reviewers provided helpful comments on earlier versions of the manuscript. The research was funded by a Natural Sciences and Engineering Research Council of Canada (NSERC) Discovery grant to M.A.B. and the WorkStudy Program of the University of New Brunswick (UNB) and Science Horizons Internship Program of Environment Canada. D.D. received financial support from the Network of Centers of Excellence for Mathematics of Information Technology and Complex Systems (MITACS), a NSERC postgraduate scholarship, a Marguerite and Murray Vaughan Fellowship in Marine Sciences (UNB) and a Board of Governors merit award (UNB).

\section{LITERATURE CITED}

Armonies W (1992) Migratory rhythms of drifting juvenile molluscs in tidal waters of the Wadden Sea. Mar Ecol Prog Ser 83:197-206

Armonies W (1996) Changes in distribution patterns of 0 -group bivalves in the Wadden Sea: byssus-drifting releases juveniles from the constraints of hydrography. J Sea Res 35:323-334

Armonies W, Hartke D (1995) Floating of mud snails Hydrobia ulvae in tidal waters of the Wadden Sea, and its implications in distribution patterns. Helgol Meersunters 49: 529-538

Barbeau MA, Grecian LA, Arnold EE, Sheahan DC, Hamilton DJ (2009) Spatial and temporal variation in the population dynamics of the intertidal amphipod Corophium volutator in the upper Bay of Fundy, Canada. J Crustac Biol 29: 491-506

Batschelet E (1981) Circular statistics in biology. Academic Press, New York, NY

Bergstrom U, Englund G, Bondsdorff E (2002) Small-scale spatial structure of Baltic Sea zoobenthos - inferring processes from patterns. J Exp Mar Biol Ecol 281:123-136

> Boates JS, Smith PC (1989) Crawling behaviour of the amphipod Corophium volutator and foraging by semipalmated sandpipers, Calidris pusilla. Can J Zool 67:457-462

> Bouma H, de Vries PP, Duiker JMC, Herman PMJ, Wolff WJ (2001) Migration of the bivalve Macoma balthica on a highly dynamic tidal flat in the Westerschelde Estuary, The Netherlands. Mar Ecol Prog Ser 224:157-170

Bringloe TT (2011) A large scale and detailed study of swimming Corophium volutator throughout the upper Bay of Fundy, including vertical distribution and timing of swimming. BSc thesis, University of New Brunswick, Fredericton

Caswell H (2001) Matrix population models. Sinauer Associates, Sunderland, MA

Coffin MRS, Drolet D, Hamilton DJ, Barbeau MA (2008) Effect of immersion at low tide on distribution and movement of the mud snail, Ilyanassa obsoleta (Say) in the upper Bay of Fundy, eastern Canada. J Exp Mar Biol Ecol 364:110-115

Commito JA, Currier CA, Kane LA, Reinsel KA, Ulm IM (1995) Dispersal dynamics of the bivalve Gemma gemma in a patchy environment. Ecol Monogr 65:1-20

Connell JH (1961) The influence of interspecific competition and other factors on the distribution of the barnacle Chthamalus stellatus. Ecology 42:710-723

> Crewe TL, Hamilton DJ, Diamond AW (2001) Effects of mesh size on sieved samples of Corophium volutator. Estuar Coast Shelf Sci 53:151-154

> Cummings VJ, Pridmore RD, Thrush SF, Hewitt JE (1995) Postsettlement movement by intertidal benthic macroinvertebrates: Do common New Zealand species drift in the water column? N Z J Mar Freshw Res 29:59-67 
Desplanque C, Mossman DJ (2004) Tides and their seminal impact on the geology, geography, history, and socioeconomics of the Bay of Fundy, eastern Canada. Atl Geol 40:1-130

- Drolet D, Barbeau MA (2006) Immersion in neutral red solution as a mass-marking technique to study the movement of the amphipod Corophium volutator. J Crustac Biol 26: 540-542

Drolet D, Barbeau MA (2009a) Diel and semi-lunar cycle in the swimming activity of the intertidal, benthic amphipod Corophium volutator in the upper Bay of Fundy, Canada. J Crustac Biol 29:51-56

> Drolet D, Barbeau MA (2009b) Differential emigration causes aggregation of the amphipod Corophium volutator (Pallas) in tide pools on mudflats of the upper Bay of Fundy, Canada. J Exp Mar Biol Ecol 370:41-47

$>$ Drolet D, Barbeau MA, Coffin MRS, Hamilton DJ (2009) Effects of the snail Ilyanassa obsoleta (Say) on dynamics of the amphipod Corophium volutator (Pallas) on an intertidal mudflat. J Exp Mar Biol Ecol 368:189-195

Emerson CW, Grant J (1991) The control of soft-shell clam (Mya arenaria) recruitment on intertidal sandflats by bedload sediment transport. Limnol Oceanogr 36:1288-1300

Flach EC (1996) Distribution of Corophium at different scales. Senckenb Marit 27:119-127

Forbes MR, McCurdy DG, Lui K, Mautner SI, Boates JS (2006) Evidence for seasonal mate limitation in populations of an intertidal amphipod, Corophium volutator (Pallas). Behav Ecol Sociobiol 60:87-95

Gray JS (1974) Animal-sediment relationships. Oceanogr Mar Biol Annu Rev 12:223-261

Gunther CP (1992) Dispersal of intertidal invertebrates: A strategy to react to disturbances of different scales? Neth J Sea Res 30:45-56

Hewitt JE, Pridmore RD, Thrush SF, Cummings VJ (1997) Assessing the short-term stability of spatial patterns of macrobenthos in a dynamic estuarine system. Limnol Oceanogr 42:282-288

Hicklin PW (1987) The migration of shorebirds in the Bay of Fundy. Wilson Bull 99:540-570

Hughes RG (1988) Dispersal by benthic invertebrates: the in situ swimming behaviour of the amphipod Corophium volutator. J Mar Biol Assoc UK 68:565-579

Hughes RG, Gerdol V (1997) Factors affecting the distribution of the amphipod Corophium volutator in estuaries in southeast England. Estuar Coast Shelf Sci 44:621-627

- Jennings LB, Hunt HL (2009) Distances of dispersal of juveniles bivalves (Mya arenaria (Linnaeus), Mercenaria mercenaria (Linnaeus), Gemma gemma (Totten)). J Exp Mar Biol Ecol 376:76-84

> Junkins R, Kelaher B, Levinton J (2006) Contributions of adult oligochaete emigration and immigration in a dynamic soft-sediment community. J Exp Mar Biol Ecol 330: $208-220$

Komatsu T, Kawai H (1992) Measurements of time-averaged intensity of water motion with plaster balls. J Oceanogr 48:353-365

Lawrie SM, Rafaelli D, Emes CH (2000) Small-scale patterns in the distribution of the amphipod Corophium volutator

Editorial responsibility: Jana Davis, Annapolis, Maryland, USA on the Ythan Estuary, Aberdeenshire, Scotland. Sarsia 85: 321-327

Legendre P, Fortin MJ (1989) Spatial pattern and ecological analysis. Vegetatio 80:107-138

Levin SA (1992) The problem of patterns and scale in ecology: the Robert H. MacArthur award lecture. Ecology 73: 1943-1967

Meadows PS (1964) Substrate selection by Corophium species: the particle size of substrates. J Anim Ecol 33: 387-394

> Mills A, Fish JD (1980) Effects of salinity and temperature on Corophium volutator and $C$. arenarium (Crustacea: Amphipoda), with particular reference to distribution. Mar Biol 58:153-161

> Norkko A, Cummings VJ, Thrush SF, Hewitt JE, Hume T (2001) Local dispersal of juvenile bivalves: implications for sandflat ecology. Mar Ecol Prog Ser 212:131-144

> Peer DL, Linkletter LE, Hicklin PW (1986) Life history and reproductive biology of Corophium volutator (Crustacea: Amphipoda) and the influence of shorebird predation on population structure in Chignecto Bay, Bay of Fundy, Canada. Neth J Sea Res 20:359-373

> Reise K (2002) Sediment mediated species interactions in coastal waters. J Sea Res 48:127-141

Roegner C, Andre C, Lidegarth M, Eckman JE, Grant J (1995) Transport of recently settled soft-shell clams (Mya arenaria L.) in laboratory flume flow. J Exp Mar Biol Ecol 187:13-26

Snelgrove PVR, Butman CA (1994) Animal sediment relationships revisited - cause versus effect. Oceanogr Mar Biol Annu Rev 32:111-177

Thrush SF, Hewitt JE, Pridmore RD (1989) Patterns in the spatial arrangements of polychaetes and bivalves in intertidal sandflats. Mar Biol 102:529-535

Thrush SF, Pridmore RD, Hewitt JE, Cummings VJ (1991) Impact of ray feeding disturbances on sandflat macrobenthos: Do communities dominated by polychaetes and shellfish respond differently? Mar Ecol Prog Ser 69: 245-252

Turchin P (1991) Translating foraging movement in heterogeneous environments into the spatial distribution of foragers. Ecology 72:1253-1266

Underwood AJ, Keough MJ (2001) Supply-side ecology — the nature and consequences of variations in recruitment of intertidal organisms. In: Bertness MD, Gaines SD, Hay ME (eds) Marine community ecology. Sinauer Associates, Sunderland, MA

- Wilson Jr WH (1989) Predation and the mediation of intraspecific competition in an infaunal community in the Bay of Fundy. J Exp Mar Biol Ecol 132:221-245

Woodin SA (1974) Polychaete abundance patterns in a marine soft-sediment environment: the importance of biological interactions. Ecol Monogr 44:171-187

Zajac RM (2004) Macrofaunal responses to pit-mound patch dynamics in an intertidal mudflat: local versus patch-type effects. J Exp Mar Biol Ecol 313:297-315

Zar JH (1999) Biostatistical analysis. Prentice Hall, Upper Saddle River, NJ

Submitted: August 15, 2010; Accepted: March 7, 2011

Proofs received from author(s): May 16, 2011 